\title{
Engineering Students' Misuse of Business Concepts: Understanding Prob- lematic Precursors to Entrepreneurship
}

\author{
Mr. Todd Mathew Fernandez, Purdue University, West Lafayette (College of Engineering)
}

Todd is a PhD Candidate in Engineering Education at Purdue University who's research is focused on entrepreneurship education as a component of modern engineering education efforts.

\section{Dr. Nathalie Duval-Couetil, Purdue University, West Lafayette (College of Engineering)}

Nathalie Duval-Couetil is the Director of the Certificate in Entrepreneurship and Innovation Program, Associate Director of the Burton D. Morgan Center, and an Associate Professor in the Department of Technology Leadership and Innovation at Purdue University. She is responsible for the launch and development of the university's multidisciplinary undergraduate entrepreneurship program, which involves 1800 students from all majors per year. She has established entrepreneurship capstone, global entrepreneurship, and women and leadership courses and initiatives at both the undergraduate and graduate levels. Prior to her work in academia, Nathalie spent several years in the field of market research and business strategy consulting in Europe and the United States with Booz Allen and Hamilton and Data and Strategies Group. She received a BA from the University of Massachusetts at Amherst, an MBA from Babson College, and MS and PhD degrees from Purdue University. She currently serves on the board of the United States Association for Small Business and Entrepreneurship in the role of Vice President for Research. She is also a Senior Research Advisor to the Stanford University Epicenter.

Connor Rene Couetil, Purdue University 


\section{Engineering Students' Misuse of Business Concepts: Understanding Problematic Precursors to Entrepreneurship}

\section{Introduction and Background}

The increased focus on entrepreneurship in engineering education ${ }^{1}$ has led to more attention being paid to what should be taught ${ }^{2}$ during these learning experiences. The general focus of has been on what students need to know to eventually behave as effective entrepreneurs. Most often, this involves the knowledge, skills, and experiences that will equip students with an 'entrepreneurial mindset, 3 . Exact definitions of 'entrepreneurial mindset' vary but generally refers to a focus on business skills and 'entrepreneurial awareness ${ }^{, 2-4}$.

There is a growing body of research focused on measuring, teaching, and organizing the content and concepts that students need to be effective entrepreneurs; however, little research has examined the preconceptions and misconceptions that engineering students have about entrepreneurship. Misconceptions involve cognitive actions that are based on incorrect underlying principles, understanding of concepts, or mental heuristics, and are independent of whether or not the correct result is achieved ${ }^{5}$. While the difference between a lack of knowledge and misconceptions may seem trivial, a growing body of research suggests that misconceptions can result in different outcomes than merely lacking knowledge. Looking at the field of physics education, researchers have explained how misconceptions can affect learning:

Analyzing thinking in terms of associational patterns leads us to suggest that when misconceptions are treated as unary and instruction focuses on trying to replace those misconceptions by correct ones, students build up alternative associational paths; one set of knowledge is activated specifically for a physics class but the other intuitive knowledge is not erased but remains for activation in all other situations. ${ }^{6}$

In other words, the authors suggest that if educators ignore misconceptions and focus merely on teaching the 'correct' concept, internalization of knowledge suffers. Students may be able to apply the concepts they are taught when in a physics classroom, however the misconceptions still exist in students' minds. More troublingly, the misconception often remain as the 'default' cognitive behavior that students prioritize over the correct approach when making or evaluating decisions quickly. Whether students use misconceptions to make decisions that are objectively correct or subjectively appropriate is not important. What is important is that students are applying rules or models that are highly risky, and the associated outcomes are unlikely to be consistently accurate or useful ${ }^{7,8}$.

A concept inventory ${ }^{9}$ is a relatively new type of assessment that can be used to assess students' misconceptions. Concept inventories are multiple choice measurement instruments provide students with answer options that are paired with explanations of why a particular choice is correct. Most commonly, they present four options referring to two potential answers; the correct answer to a particular problem is presented twice, once with a conceptually correct explanation, and once with a conceptually incorrect answer. By assessing whether students choose the right answer for the right reason, educators are able to assess whether students understand a concept, or whether they rely on a misconception to obtain a correct answer. 
Misconceptions are especially important and relevant, in the field of entrepreneurship for a number of reasons. Misconceptions are hard to observe and difficult to separate from 'simple' mistakes ${ }^{9}$. The high propensity for failure in entrepreneurship makes it difficult to separate misconceptions from mistakes or bad luck. Further, the strong and growing public focus on entrepreneurship provides a stream of information about entrepreneurship and entrepreneurs themselves that, at times, can have a complex and tense relationship with entrepreneurship theory and pedagogy ${ }^{10}$. Misconceptions about entrepreneurship are critical to engineering students for two reasons. First, the scope and depth of business concepts presented to engineering students is inevitably narrower than it is for business students exposed to a portfolio of concepts during the course of a four year business degree ${ }^{11}$. Second, the societal and cultural excitement surrounding technical entrepreneurship has resulted in media constructions of entrepreneurs and entrepreneurship that may not accurately reflect the characteristics or experiences of the general population of "real entrepreneurs"10,12.

Within this context, understanding the misconceptions students have constructed about entrepreneurial action and business concepts is critical to entrepreneurship education. Knowing the specific misconceptions engineering students have, will allow entrepreneurship education to deliberately challenge and address them. This in turn, will develop more effective entrepreneurs because their abilities will be grounded in sound and well applied business principles.

\section{Purpose of the study}

The purpose of this study is to examine the misconceptions on which engineering students rely when solving entrepreneurially-framed business problems. More specifically, it explores what categories or themes of misconceptions are common among engineering undergraduates who have, and who have not, been exposed to entrepreneurship education.

\section{Methods}

The paper applies thematic analysis to a qualitative data set comprised of qualitative interviews performed with 40 engineering undergraduates. As part of the interview protocol students worked through an entrepreneurial scenario and were asked to make business decisions, as a means to examine whether they used effectual versus predictive decision making approaches ${ }^{15}$. Interview data were transcribed and analyzed by two coders to identify misconceptions. A pilesort method was used to categorize the misconceptions into thematic groups, which could then be explained in relation to established business concepts. All work was checked by a third, researcher who was not involved in the coding or theme identification process. The methodological approach is described in more detail below.

\section{Population}

The population consisted of engineering undergraduates from two Midwestern universities. The first university is smaller, primarily undergraduate, private university, while the second is a large, research-intensive, public university. Both universities have extensive entrepreneurial programs available to engineering students.

Using an IRB approved protocol students were recruited for the study via emails from their departments and faculty. The study was designed to collect similar samples from each university, in terms of number of interviews conducted, gender, and whether they had exposure to 
entrepreneurship education or not. Those who had completed either academic credentials or significant coursework in entrepreneurship were classified as 'entrepreneurial' based on data collected through a demographic survey, prior to the start of the interview.

In total, data was collected from 40 students, 20 from each university. The larger, public university's participants were evenly split between entrepreneurship and non-entrepreneurship students. At the private university, 8 of 20 respondents were classified as entrepreneurial. The sample consisted of 28 male students and 18 female students. All but 2 students indicated that they had completed at least one engineering internship. Students also identified as entrepreneurs themselves ( 5 of 40), having an entrepreneur in the family (11 of 40), or having a close friend who had participated in an entrepreneurial venture in the past (19 of 40).

\section{Data Collection}

Interview transcripts were the primary data source. The demographic survey was administered to participants to characterize and describe the sample. Interviews were conducted in person and lasted approximately 45 minutes to one hour. Two interviewers conducted all of the interviews, with one conducting 33 and the other conducting the remaining 7.

The interviews were primarily organized around a verbal protocol ${ }^{13,14}$, derived from that used by Sarasvathy ${ }^{15}$ in her study of effectuation. Based on the results of a pilot study, some modifications were made to increase the ability to differentiate use of effectual and causal logic by undergraduate students ${ }^{16}$. The protocol asked students to solve a series of problems related to an entrepreneurial scenario while thinking aloud. The scenario was representative of an early stage software development business. Within it, participants reasoned through nine problems requiring decisions that ranged from gathering early stage funding, to human resources concerns, and exit opportunities.

Interviews were audio recorded and then transcribed. Interviewers prompted or encouraged students to continue talking when they became quiet. Interviewers asked follow-up questions to probe unclear thinking or delve more deeply into specific lines of thinking.

\section{Codes and coding process}

Two coders analyzed the transcripts. One is a graduate researcher assistant with significant business management and entrepreneurship experience who teaches a multidisciplinary, introductory entrepreneurship course. The second is an undergraduate research assistant majoring in computer science who received an entrepreneurship credential and has had several internships as a financial and market analyst. All coding and analysis work was then checked by a third researcher who is a long time entrepreneurship education researcher, tenured faculty member, and director of entrepreneurship education programs.

The coding process occurred in two stages. In the first stage, each coder read all 40 transcripts individually and tagged any misconceptions they observed. To each misconception tagged they also provided an explanation of why the text represented a misconception and what concept the student had a misconception about. After both coders had coded all 40 transcripts, the coded misconceptions were compiled by one of the coders. 
In the second stage, both coders worked together to review each misconception, with the original coder blinded. The coders reviewed and discussed both the coded text and the associated explanations. If both coders agreed that the text represented a misconception, the coded text was retained. If either coder disagreed, the coded text was eliminated from the dataset. Because of the lack of prior research in this area, and the exploratory nature of our interest in students' misconceptions, a generally open approach to coding and tracking misconceptions was taken.

Coded misconceptions were defined as 'a business or management concept which is applied incorrectly, makes objectively unreasonable assumptions, or is based on significant misconceptions or misinformation'. The definition drew on descriptions and definitions of 'misconception' in educational literature ${ }^{9,17,18}$. Coders ignored opinion statements and mathematical mistakes made by students. In general, misconceptions were interpreted as instances where students had incorrect knowledge at a specific conceptual level, as opposed to not answering correctly due to a lack of knowledge.

Coders intentionally applied codes generously in the initial coding process. The liberal coding enabled broad initial identification of what might be consistent business misconceptions amongst students and acknowledged the different ways in which misconceptions might manifest (e.g., through analytical choices, assumptions, etc.). Because the process occurred in multiple stages, with the second stage blindly assessing each coded segment, the more liberal coding was appropriate. The 'default to tag' behavior by the coders in the initial stage, combined with the explanations, increased the ability to refine the coded data at the second stage.

\section{Theme identification}

When the coding process was complete, the iterative process of theme identification began. The process for theme identification followed a pile sort method ${ }^{19}$ as described in the engineering education literature $^{20}$. Agreement was sought among both coders and a third, non-coding, researcher. To execute the process, all of the coded misconceptions were printed and cut into individual slips of paper which contained the text of the misconception and a number identifying the chunk of text or data. They did not identify the case name or the coder's explanation of the misconception to prevent biasing or grouping based on non-text variables.

The slips of paper were then sorted into piles. The process involved reading and creating preliminary themes with no preconditions on the number of piles. Each pile was then refined and iterated by moving items between piles to more clearly identify conceptual boundaries. General theme descriptions were written on extra paper to label each group. Each individual chunk was then tested against the description, thereby refining the inclusion of chunks as well as the descriptions of the piles. After completing the process, several 'themes of one' remained. While these were misconceptions, they did not match with other examples of the same conceptual misunderstanding and were removed.

\section{Modeling of theme and misconceptions}

After theme identifying, two mathematical models were used to explore the relationship between demographic variables and misconceptions. Specifically, we used regression models to look for meaningful predictors of either the quantity of misconceptions or the presence of a specific theme. We present the models only as initial steps towards future work that will benefit from larger sample sizes. Both models were run using R statistical programming software. 
The first model used linear regression to explore the relationship between the demographic survey variables and the number of misconceptions in a protocol. Variables from the demographic survey were used as predictors of the number of misconceptions in the final data set for each individual case. The linear regression models were run twice. First, each demographic variable was run as the single predictor in a model with the number of coded misconceptions as the outcome. This allowed us to assess the individual effect of each variable separately. After running each model, we ran a single model using all of the variables as predictors simultaneously. This model was intended simply to assess the potential for interactions among different variables, the individual predictor model remains the primary analysis

The second model used a logistic model to predict the presence or absence of a given theme in an individual students' protocol. The logistic model treats outcome variables as having a binary outcome. In this case, the binary outcome represents the presence or lack of a given theme within each protocol coded as a 1 or 0 respectively. As with the first model, we ran each predictor separately for each theme.

\section{Results}

\section{Quantity of Misconceptions}

The first coding stage identified 257 misconceptions; the first coder identified 146 misconceptions in 38 of 40 cases, and the second coder identified 111 misconceptions in 37 of 40 cases. The number of misconceptions per case (i.e., individual interviewee) ranged from 0 to 18 (an outlier in the sample). The average number of misconceptions per case per coder was 6.4, the median number of coded misconceptions was 3 , and the mode was 2 . The coded segments representing misconceptions ranged from 3 to 420 words in length

When going through the code refinement process, of the 257 misconceptions, the coders matched exactly (i.e., same starting and ending points with same description) on 20, leaving 237 unique chunks for further analysis. While this appears to be a low level of 'agreement', it is both acceptable and preferred in this study. The goal of the initial reading of the data was not to identify identical misconceptions, but to cast a wide net and identify all potential misconceptions.

Both coders then reviewed all 237 coded instances together. At this stage, several chunks were combined to form larger misconceptions where coders identified different but overlapping portions of text as a misconception. The final data set consisted of 112 misconceptions identified in 36 of 40 cases.

\section{Themes}

The pile sort method was then applied to the 112 misconceptions for theme identification. Four primary themes were identified and 103 of the 112 were attributed to these four themes. The remaining 9 represented a variety of misconceptions found in single cases. The section below describes each of the four themes and representative quotes from student interview transcripts.

\section{Venture Ownership and Exiting}

The first theme involved misconceptions about ownership, equity, and control when exiting a business. At the end of the interview protocol, students were presented with the scenario below 
that involved them making a decision about whether to exit the venture or engage in an Initial Public Offering (IPO):

In the $10^{\text {th }}$ year of the company, you are doing $\$ 70$ million in sales and project that you will reach $\$ 100$ million within a year. At this time, you see 2 possible directions for the company:

1) Take the company public. Your accountants suggest that you should offer 2 million (of your total 12 million shares) at $\$ 30$ per share.

2) Disney, which has been trying to get into the educational software market, offers you $\$ 420$ million for your entire company.

Students often gave clear answers that analyzed their personal interests, long term career goals, and assessments of value. However, close to half of the students (16 of 40) also struggled with the exact mechanisms at play when choosing among these two paths. The most obvious misconception was that if they choose option 2, they would receive the entirety of the $\$ 420$ million offered by Disney. This despite the fact that distribution of equity had occurred earlier in the verbal protocol scenario. Therefore, students conflated the value of the company with the compensation they would receive. The most direct example of this theme came from Robert.

\section{I can't see a problem with having $\$ 420$ million in my pocket $\sim$ Robert}

Others, acknowledged that they were not entirely sure of the mechanisms at play when a company purchases another company, but still assumed that they would see the complete financial windfall. These assumptions are in direct conflict with data related to the level of founder ownership when they exit a venture ${ }^{21}$. A review of SEC filings for 79 tech IPOs, found average company ownership for company founders at exit was $17 \%$, a value heightened by several outliers (e.g., Facebook at 57\%). The median was $11 \%$.

And Disney wants to buy us out at $\$ 420$ million. Mm-hmm- $\$ 420$ million. And that would - I would assume that would go to me. I'm not sure how that would work out. Mason

In addition to misconceptions about financial windfall at company exit, students also had misconceptions about who controls a company after an IPO. Not surprisingly, undergraduates are unaware of the many elements and nuances associated with exerting control over a company's direction and management after an IPO. This is evident in Alexander's assumption that he will retain control of company post-IPO.

Well, if you go public, you can obviously keep running the company the way you want to run the company, -Alexander

To summarize this category of misconceptions, when given two options for exiting an entrepreneurial business, the engineering students interviewed struggled with basic misconceptions associated with the mechanics and meaning of critical business transactions. Their statements suggest that they conflate themselves as individuals, with the business entity. While they thoughtfully evaluated the options, they did so based on the faulty assumptions that 
founders receive all proceeds from the sale of a business, and that they would be able to maintain control post-IPO. While there may be cases when this is true they directly conflicted with information provided earlier in the scenario and are more the extreme exception rather than the rule in practice.

\section{Taking investment}

The second misconception theme revolved around the process of taking outside investment as an early stage venture. The students were provided with information about early sales and success of their product. They were then asked to choose one of three options to raise funding to continue growth, as shown below:

You estimate you will need $\$ 5$ million to break even, and given your sales projections, it will take about 2 years before you reach that point.

You have 3 financing options:

Option 1: A venture capital firm from the digital entertainment industry offers $\$ 5$ million for $30 \%$ of the company.

Option 2: A family friend with extensive experience in selling educational products wants to partner. He wants to invest $\$ 5$ million for $30 \%$, but also wants to work for the company for a $\$ 200,000$ yearly salary.

Option 3: You continue to bootstrap the company with internal cash, growing at a slower pace.

In general, student logic revolved around weighing elements of risk and control when assessing each option. Apparent in that weighing of options were basic misconceptions about the paths to, and the realities of, receiving outside investment. For example, Isabella assumed that personal characteristics like charisma would make VC investment easy to find:

I would pick the venture capitalists. I think I'm like pretty charismatic, so it wouldn't be that hard to find them, Isabella

While charisma is unlikely to be a detriment to company success, empirical data suggests that VC investment is difficult to obtain. The difficulty is something we suspect many students significantly underestimate, given the discourse surrounding venture capital in the entrepreneurial community and even within entrepreneurship education programs. Research suggests that only around $10 \%$ of VC deals are initiated by cold calls, including both investors contacting ventures and ventures contacting investors ${ }^{22,23}$. Further, research published by VC firms suggests that investment occurs only in $0.1 \%-1 \%$ of the firms that a VC firm initiates contact with, and most potential $\mathrm{VC}$ deals end at the initial business review (i.e., pre-meeting) and due diligence stages, where the influence of personal characteristics may be minimal..

This comment is also at the heart of a basic understanding of misconceptions. Isabella choose to build part of her analysis on the ability to gain access to VC organizations. However, access had already been asserted in the protocol, making success access irrelevant. Similar to the example from physics education, what this shows is how the misconceptions can manifest in somewhat 
strange ways to influence thinking. In this case, the ease of access is both incorrect given data on $\mathrm{VC}$ deal flow and irrelevant to the analysis she is performing.

We also found multiple students who had misconceptions regarding changes in management. For example, Eric wants to be clear with the VC's or Family Friend on two points. First, he insists that he retain control of the direction and decision making associated with his venture. Again, lacking knowledge about equity as described in the previous section, but also the common practice of a $\mathrm{VC}$ and/or major investor taking at least one board seat at any companies in which they invest, and the subsequent realities of battles for control that are common when investment events occur ${ }^{24}$ :

So as long as like - I would need her to assume me that I'm in charge and that if I want to drop this at any time, like it's not going to hurt me - like that sort of agreement. It's not going to come back to bite me or anything like that $\sim$ Eric

Eric's second insistence, is that he be allowed to drop the project at any time, is likely equally problematic from an investor point of view. Many investors focus on the team as a significant element of an investment. Requiring pre-investment agreement that he may leave would likely indicate to an investor, whether VC or family friend, that he is not serious about the venture and that investment might be unwise if Eric is viewed as critical to success.

In summary, students have misconceptions about the ease and process by which venture investment is likely to occur. They believe that gaining VC funding is fairly easy and driven by their own skills rather than the details of the venture and its potential. Further, they seem unaware of the realities that occur when companies do invest and the expectations and agreements attached to such investments.

\section{Pricing and market research}

The third misconception theme involves how students operationalized pricing and market research data. Students were given two pages of primary and secondary market research, including data from multiple customer interviews describing how much they would be willing to pay for the product. Students were asked to answer four questions using that data:

Who will your primary customers will be?

Through what channels will you sell the product?

How will you choose a price for the product?

Based on all of this information, how do you decide whether there is enough potential value to start selling the product to the market you developed?

An example of the data that students were provided appears in Table 1. 
Table 1 Market research data provided to participants

Survey 1: Given to people who downloaded a demo of the game online

\begin{tabular}{llll} 
Willing to pay $(\$)$ & Young adults $(\%)$ & Adults $(\%)$ & Educators $(\%)$ \\
$50-100$ & 45 & 26 & 52 \\
$100-150$ & 32 & 38 & 30 \\
$150-200$ & 15 & 22 & 16 \\
$200-250$ & 8 & 9 & 2 \\
$250-300$ & 0 & 5 & 0 \\
\hline Total & 100 & 100 & 100
\end{tabular}

The most common element of this misconception is represented by Emma's assertion below. She assumes a direct relationship between profitability and price paid. The data presented also estimates market size. Students tended to make the conception that higher prices would automatically result in higher revenue. This misconception occurred in 15 of 40 cases.

[I] guess adults are willing to pay more for it. So I would focus on adults. So what's the kind of logic behind that, the - saying just - so what's it mean to you to have them be more - willing to pay a higher price point? That just means that it's more profitability for me. Emma

Students were also given information on the number of potential consumers in a given group. The data allowed students to make a comparison of revenue by combining market size with potential revenue. However, few students made the effort during the study to integrate the two data sources. While we expect that engineering students, especially students' with entrepreneurial coursework, are capable of integrating those pieces of data if given more time, it is insightful that this misconception occurs when needing to interpret data quickly, which can be key in the early stages of a business.

In addition to struggling to make assessments of potential revenue, students also tended to struggle with narrowing sales to a single market. When presented with data in Table 1, some students had difficulty interpreting the cumulatively formatted pricing data. This was exemplified by Daniel, as shown in the quote below:

So if you have - so if you're going to sell to - if you - say you price it at $\$ 125$ and you sell 32\% to young - the young adult market and 38\% to the adult market and $30 \%$ to the educators' market, then you can figure out how much money you're going to make based off the size, based off the interest, and based off the price, and you can tell how many units you're going to move, how many - how much infrastructure, and so from there, you can actually even take this into effect whether you sell it by internet and - so you could bring up a spreadsheet, essentially, to calculate if we sell it for 50-100, how much money are we going to make? How many - if we sell it for 100-150, how much money are we going to make that way? And then whichever number is the largest or from kind of an ethical business standpoint $\sim$ Daniel 
What Daniel does, which was far from unique in our data, is assume that pricing categories are can be summed either down or across the table. He assumes that those willing to pay a higher price will not purchase the product at a lower price. Further, despite the request to select a single market to sell to, he assumes that for a given price the venture will begin by targeting and capturing all three markets simultaneously. While Daniel does acknowledge and correctly explain the path to creating a full revenue estimate, his answer is representative of why this misconception is so critical. In all coded manifestations associated with this theme, the misconception would result in significant overestimation of revenue.

\section{Market share vs. market size}

The final theme identified came from assumptions made about market size and market share. While this theme was much rarer, occurring in only 6 of 40 cases, it occurred multiple times in each of those 6 cases. Students assumed that the size of a market is not just directly representative of the size of the company, but that the market size is the company size. This assumption of $100 \%$ market share vastly overestimates the value of ventures and disrupts assessments of investment and exit decisions. Not surprisingly, this is the only theme that occurred in multiple parts of the protocol, for each of the 6 participants. The primary example of this theme comes from Todd's protocol:

$$
\begin{aligned}
& \text { [It] would probably be very good given that there was approximately } \$ 1.7 \text { billion } \\
& \text { in instructional technology. So that would be who he would be working with the } \\
& \text { most, and so if it's } \$ 5 \text { million that he would be investing, and then the estimated } \\
& \text { value is } 1.7 \text { billion with } 20 \% \text { growth, I guess this would be a couple of years down } \\
& \text { the road. It'd be even higher than that. The } 20 \% \text { per year for the next five years } \\
& \text { could - at the end of these five years where it's expected to grow, it'd be worth- } \\
& \text { just like the rough numbers, it'd be like } \$ 3 \text { billion for a } \$ 5 \text { million investment that } \\
& \text { someone gets } 30 \% \text { of. } \sim \text { Todd }
\end{aligned}
$$

Given the broad market definition of 'instructional technology' in this scenario, Todd confounds the market size, $\$ 1.7$ billion, and the company's value. Todd makes this analysis in the context of deciding on which of the three early stage investment options he would choose from and is assessing a $\$ 5$ million dollar investment for $30 \%$ of the company at a valuation of the company. This represents two distinct but interwoven problems. First is the assumption that his venture captures the entirety of the $\$ 1.7$ billion dollar market for instructional technology with a single entrepreneurial simulation game. Second, he conflates sales revenue with a direct valuation of the company.

While not going as far as Todd, Liam also operationalizes the same misconception. When deciding on which market to pursue, Liam eyes the instructional market size as an enormous opportunity to pursue.

So it says that the market here - the instructional and technology and simulation games are pretty big. It's like two-and-a-half billion dollars, and they're expected to grow $20 \%$ over the next five years - or $20 \%$ per year for the next five years. So, I mean, that'd be a pretty big market for just one game. Liam 


\section{Modeling of themes and codes}

The tables below present probability values indicating the statistical significance of each demographic variable for two models. The first, Table 2, shows the probabilities from a model predicting the number of misconceptions that would be identified in a given individual protocol. The first results column presents the probability that each demographic variable predicts the number of misconceptions in a case. The second column shows probability values of a model with all predictors included.

The results of the linear model in Table 2 show that the demographic predictors have little impact on the number of misconceptions in a given case. In both cases, the only predictor which is statistically significant is gender. In both cases, male students are predicted to have approximately 1.5 less misconceptions than female students. Given the smaller number of female cases (12 vs. 28), we suspected that this may be an outlier effect of one high female case.

Running the models without the outlier case gave nonsignificant results. More interestingly, were the results suggesting that neither entrepreneurship coursework nor prior involvement in entrepreneurship via family or friends entrepreneurship, were significant.

Table 2 p values from linear model predicting the number of misconceptions per case

\begin{tabular}{|c|c|c|}
\hline Variable & Individual Predictors & All predictors \\
\hline University & .06 & .41 \\
\hline Entrepreneurship coursework & .11 & .40 \\
\hline Interviewer & .83 & .96 \\
\hline Gender & $.02^{1}(.35)$ & $.01^{1}(.29)$ \\
\hline Age & .63 & .53 \\
\hline Years of work & .38 & .30 \\
\hline Internship & .31 & .21 \\
\hline Ent. Family & .76 & .15 \\
\hline Ent. Friend & .25 & .24 \\
\hline Ent. Self & .76 & .87 \\
\hline
\end{tabular}

Table 3, on the following page, presents the results from the logistic regression model. The results suggest that, similar to the number of misconceptions model, the demographic predictors do not meaningfully explain the presence or absence of a given theme in a given case. Only two $p$ values met the standard $p<.05$ criteria for significance. The first significant results suggests that the presence of the venture ownership and exiting theme is influenced by university. The results showed that University 1, the private university, had a significantly higher prevalence of misconceptions around entrepreneurial exits than did University 2. 
Table 3 p values predicting the presence or absence of each theme in an individual case

\begin{tabular}{|c|c|c|c|c|}
\hline Variable & Exiting & Investment & Pricing & Market Share \\
\hline University & .007 & .73 & .90 & .21 \\
\hline Ent. Coursework & .16 & .02 & .11 & .94 \\
\hline Gender & .60 & .06 & .78 & .99 \\
\hline Age & .67 & .51 & .86 & .35 \\
\hline Years of work & .80 & .15 & .67 & .27 \\
\hline Internship & .53 & .99 & .99 & .78 \\
\hline Ent. Family & .44 & .10 & .25 & .61 \\
\hline Ent. Friends & .68 & .95 & .68 & .53 \\
\hline Ent. Self & .08 & .70 & .99 & .94 \\
\hline Count of Misconceptions & .33 & .62 & .85 & .62 \\
\hline \multicolumn{5}{|c|}{$\begin{array}{l}\text { Note: Bolding highlights } p \text { values <.05, each cell represents an individually run } \\
\text { logistic model with the variable (row) as the sole predictor and the theme (column) as } \\
\text { the sole predicted outcome, } N=40 \text { for each model. }\end{array}$} \\
\hline
\end{tabular}

The second significant result involved the investment misconceptions theme and entrepreneurial coursework. Students who had completed entrepreneurial coursework were significantly less likely to have investment misconceptions. As we will explain in the discussion and conclusions section, the lack of significant predictors is as insightful at this exploratory stage as would be a large number of significant predictors.

\section{Discussion and Conclusions}

The purpose of this paper was to examine the misconceptions engineering students have about entrepreneurship to identify areas that should be addressed in education. We identified four themes of misconceptions that engineering students demonstrated when solving entrepreneurial problems. We also examined what demographic variables were statistically significant as predictors of the overall prevalence of misconceptions and the presence of the four identified themes in individual cases. We propose an interpretation of those themes and the implications of this exploratory research for engineering entrepreneurship educators.

The study identified a set of consistent and conceptually identical misconceptions that are differentiated from mistakes. The fact that students have misconceptions is not unacceptable, but understanding the misconceptions, their root, their form, and solutions will be useful to engineering entrepreneurship educators. The fact that these themes appeared so consistently across two universities and multiple student paths demonstrates that there are clearly concepts on which students actively hold false assumptions and expectations regarding work in entrepreneurial companies. This suggests that students have over-optimistic views of entrepreneurship that may driven by environmental or cultural factors such as how entrepreneurship is portrayed in the media. Or, it may reflect how entrepreneurship is being taught at universities where student and faculty involvement in startups is increasingly promoted as a measure of success. This suggests that entrepreneurship education programs should make a concerted effort to provide students with realistic assessments of the range of decisions and outcomes they will face as entrepreneurs, and/or as engineers involved in business endeavors. 


\section{Misconceptions vs. mistakes: Interpreting the four themes}

In perhaps the most foundational work on the impact of cognitive misconceptions, Tversky and Kahneman ${ }^{5}$ show that mental shortcuts (which they call 'heuristics') are heavily engrained in individuals. They also show that problematic heuristics are present even in very experienced individuals. For example, they found that individuals with $\mathrm{PhDs}$ in statistics used the same misconceptions as those with minimal or no formal statistical training. However, no one would suggest that a PhD. in statistics would be unable to perform basic statistical computations. What is critical in the discussions of misconceptions is separating engrained automatic behaviors from assumptions about fully rational human behavior, i.e., bounded rationality ${ }^{25,26}$.

We interpret the consistent and conceptually similar ways of thinking that manifest across multiple protocols as representing misconceptions rather than simple mistakes or lack of knowledge. As such, just as with misconceptions in other fields ${ }^{27,28}$ they require educational strategies that go beyond teaching the correct approach and, instead, intentionally disrupt the basic views of entrepreneurship that students have constructed. In turn, that disruption will also inform their conceptualization of entrepreneurial decision making at basic levels.

Notably, in many cases where students used misconceptions, they managed to correctly recall, retrieve, and apply conceptual or mathematical models related to those misconceptions. The misconceptions influenced the assumptions students applied to those models and they retained them throughout. For example, many students correctly integrated the evaluation of investment options and market research to establish valuations and make investment decisions. However, their misconceptions about market size (i.e., assuming 100\% market share) were reflected in their evaluation of investment options as well, despite being entirely different section of the protocol.

The repeated reuse of a misconception suggests an unattended metacognitive failure ${ }^{29}$. Research has suggested metacognition is a key feature of entrepreneurial expertise ${ }^{30}$. Students' overlooking analyses that result in highly problematic outcomes suggests unattended metacognitive failure ${ }^{31}$. These specific metacognitive failures arise in part from the misconceptions which incorrectly make several of the overestimations of value, growth, market size, and revenue appear reasonable. Because of these misconceptions, and their underlying sources, which we turn to in the next paragraph, the 'mistakes' are not identified, never addressed, and allowed to manifest with other knowledge constructed upon it, as has been demonstrated in other misconception research ${ }^{6}$.

What we see as common among the four themes discussed is that they align strongly with research related the mythicization and public reification of entrepreneurs ${ }^{10}$. We suggest that at the root of both the exiting and investment decisions is the perception of 'the entrepreneur' that is portrayed in media and social representations of entrepreneurship. The reification of highly visible and successful individual entrepreneurs such as Mark Zuckerberg, Elon Musk, and Bill Gates contribute to the entrepreneurial identity formation that students before students enter the entrepreneurial classroom.

A common aspect of both the exiting and investing themes was that the student believed that he/she would be able to demand, assert, and retain control of the venture, even after taking outside financing. Again, students often see articles and news reports touting 'the coolest 30 
entrepreneurs under 30' but less rarely see media discussions what happens on a day-to-day basis, behind the scenes, with advisors, investors, boards and other influencers ${ }^{32}$. Instead, the mythicized individual entrepreneur is firmly attached to a narrative focused on the control and success of a firm, especially in the area of high-tech entrepreneurship that seems most relatable to engineering students. Presented with such narratives constantly, it is not surprising that misconceptions about control and power influence decision making in young entrepreneurs.

A similar analysis is apparent in the themes related to pricing and market share. Just as the social narrative of entrepreneurship focuses on individual entrepreneurs, it also focuses on extremely rapid and high growth entrepreneurial venture. If students' conception of entrepreneurial ventures is primarily framed by highly value, rapid growth companies such as Facebook, Tesla, and Microsoft these themes make sense. Both Facebook and Micorosft are characterized by their enormous, and relatively captive user base. Further, they and many other Silicon Valley startups, exist at valuations that make a 10 -yr old $\$ 1.7$ billion dollar company seem quite reasonable despite the much smaller revenues presented in the protocol.

\section{Implications for engineering entrepreneurship education}

Overall, the results of this study suggest that there is a very limited relationship between misconceptions and entrepreneurial education, which is interesting but not entirely surprising. The modeling results show that, except in two cases, there is no relationship between the themes identified and student demographics. In only theme was entrepreneurship coursework a predictor of a lower level of misconception. That theme showed that participation in education reduced the prevalence of misconceptions related to investment. The only other statistically significant outcome was that one university had fewer misconceptions related to venture exiting.

It is useful to situate these results within the learning objectives taken from the syllabi of the larger university's introductory entrepreneurship course, which 10 of the students had taken. These include:

\section{Understand how to create economic and social value from your knowledge}

Develop a mindset and tools to identify and evaluate opportunity and risk associated with new venture development

Construct a plan to identify, design, and deliver a new product, technology, or venture

Understand how market research and feasibility analysis are used to make a compelling case for launching or not launching a new venture

Analyze methods to evaluate, acquire, and manage scarce financial and non-financial resources for a proposed venture

Recognize one's own entrepreneurial potential and ways to capitalize on it Execute the steps associated with new venture formation and development

As noted earlier, the graduate student researcher is an instructor in this multidisciplinary introductory entrepreneurship course. In interactions with those teaching other sections, and his own experience, he has noticed that the investment misconceptions are constantly challenged throughout his and others sections of the course, and are framed specifically around issues of an 
entrepreneur's control within those decisions. While discussions of exiting or investment may not be explicit, they are implicit in multiple learning objectives or included as content in the course. In comparison, market analysis and selection of target markets are key concepts, and are presented within the context of deciding which opportunity to pursue. They are not presented in ways that are likely to force students to clearly understand the tension between market share and market size or involve the actual pricing and sale of a product for a specific market segment.

Given these findings, the graduate researcher/instructor has already made changes based on the results of this study. These include a heavier focus on the conceptual mechanics and explicit and implicit roles of entrepreneurial stakeholders. These changes include a greater focus specifically on the role of boards of directors, pragmatic examples of how early stage investment works in practice, and discussions of what individual entrepreneurs can and cannot control as their venture grows and takes shape. Specific examples of failed ventures, exits forced against entrepreneur's wishes, data on founder ownership stake, and referencing of board membership not just founders when discussing existing ventures are now included. Finally, he has added a module specifically on understanding and analyzing market share vs. market size. The change in language and examples are intended to disrupt the narrative of the highly successful individual entrepreneurship that seems at the root of the four themes.

In sum, what our results suggest are fairly small changes in support of models already prevalent in engineering entrepreneurship education. The changes include a need to confront misconceptions directly ${ }^{6}$ and to make those misconceptions directly visible to students and educators ${ }^{7,8}$. Within the experiential, active, and project based learning environments common to engineering entrepreneurship education ${ }^{11}$ the framing of examples and activities can be used to disrupt these common narratives.

We would suggest two adjustments that instructors can do to help eliminate these misconception themes from their classrooms. First, place and teach to students from more roles than just that of 'entrepreneur'. Actively engaging students in analyzing new ventures from the point of view of a board member or VC provides a different set of needs and goals. Second, be attentive and conscious of where societal narratives of entrepreneurship are adopted in your classroom and seek to challenge them. This likely involves the acknowledgment, explanation, and deconstruction of what those narratives are, why they are problematic, and when they are or are not appropriate.

\section{References}

1. Jamieson, L. H. \& Lohmann, J. R. Innovation with Impact. ASEE Conf. Plenary (2012).

2. Kriewall, T. J. \& Mekemson, K. Instilling the entrepreneurial mindset into engineering. $J$. Eng. Entrep. 1, 5-19 (2010).

3. Solesvik, M. Z., Westhead, P., Matlay, H. \& Parsyak, V. N. Entrepreneurial assets and mindsets: Benefit from university entrepreneurship education investment. Educ. + Train. 55, 748-762 (2013).

4. Kleine, R. E. \& Yoder, J. Operationalizing and Assessing the Entrepreneurial Mindset : A Rubric Based Approach. 2, 57-86 (2011). 
5. Tversky, A. \& Kahneman, D. Judgment under uncertainty: Heuristics and biases. Science (80-. ). 185, 1124-1131 (1974).

6. Redish, E. F. \& Smith, K. a. Looking Beyond Content : Skill Development for Engineers. J. Eng. Educ. 97, 295-307 (2008).

7. Steif, P. S. (Carnegie M. U. \& Hansel, M. a (Robert M. U. New Practices for Administering and Analyzing the Results of Concept Inventories. J. Eng. Educ. 205-212 (2007).

8. Streveler, R. A. et al. Rigorous Methodology for Concept Inventory Development: Using the'Assessment Triangle'to Develop and Test the Thermal and Transport Science Concept Inventory (TTCI). Int. J. Eng. Educ. 27, 968 (2011).

9. Jorion, N. et al. An Analytic Framework for Evaluating the Validity of Concept Inventory Claims. J. Eng. Educ. 104, 454-496 (2015).

10. Ogbor, J. O. \& Avenue, C. Mythicizing and reification in entrepreneurial discourse: ideology-critique of entrepreneurial studies. J. Manag. Stud. 37, 605-635 (2000).

11. Fiet, J. O. The Pedagogical Side of Entrepreneurship Theory. J. Bus. Ventur. 16, 101-117 (2001).

12. Iyer, R. Entrepreneurial identities and the problematic of subjectivity in media-mediated discourses. Discourse Soc. 20, 241-263 (2009).

13. Chi, M. T. H. Quantifying Qualitative Analyses of Verbal Data: A Practical Guide. J. Learn. Sci. 6, 271-315 (1997).

14. Simon, H. A. \& Ericsson, K. A. Verbal reports as data. Psychol. Rev. 87, 215-251 (1980).

15. Sarasvathy, S. D. Effectuation: elements of entrepreneurial expertise. (Edward Elgar Publishing Limited, 2008).

16. Wheadon, J. D. \& Duval-Couetil, N. Effectual Logic as a Means to Measure the Entrepreneurial Thinking of Engineering Students. United States Assoc. Small Bus. Entrep. Conf. Proc. HM1 (2016).

17. Prince, M., Vigeant, M. \& Nottis, K. Development of the heat and energy concept inventory: Preliminary results on the prevalence and persistence of engineering students' misconceptions. J. Eng. Educ. 101, 412-438 (2012).

18. Chen, J. C., Whittinghill, D. C. \& Kadlowec, J. a. Classes that click: Fast, rich feedback to enhance student learning and satisfaction. J. Eng. Educ. 159-168 (2010). doi:10.1002/j.2168-9830.2010.tb01052.x

19. Ryan, G. W. \& Bernard, H. R. Techniques to identify themes. Field methods 15, 85-109 (2003). 
20. Daly, S. R., Adams, R. S. \& Bodner, A. M. What does it mean to design? A qualitative investigation of design professionals' experiences. J. Eng. Educ. 101, 187-219 (2012).

21. Abdullah, S. The median level of founder ownership at exit. (2016). Available at: http://blossomstreetventures.com/blog_details.php?bcat_id=106.

22. Merrill DataSite. Survey report: Sourcing the deal in the mid market. (2010).

23. Teten, D. Where are the Deals? How VCs Identify the Next Generation of Winning Companies. (2014). Available at: http://teten.com/blog/2014/02/03/8724/.

24. Solomon, S. D. A Lesson in Control. The New York Times (2010).

25. Simon, H. A. Models of man: Social and rational. (Wiley, 1957).

26. Simon, H. A. Rational choice and the structure of the environment. Psychol. Rev. 63, 129138 (1956).

27. Weber, N. R. et al. First-year students' environmental awareness and understanding of environmental sustainability through a life cycle assessment module. J. Eng. Educ. 103, 154-181 (2014).

28. Crismond, D. P. \& ADAMS, R. S. The informed design teaching and learning matrix. J. Eng. Educ. 101, 738-797 (2012).

29. Goos, M. Understanding metacognitive failure. J. Math. Behav. 21, 283-302 (2002).

30. Haynie, J. M., Shepherd, D., Mosakowski, E. \& Earley, P. C. A situated metacognitive model of the entrepreneurial mindset. J. Bus. Ventur. 25, 217-229 (2010).

31. Goos, M. Understanding metacognitive failure. J. Math. Behav. 21, 283-302 (2002).

32. Fenn, D. 30 coolest entreprenuers under 30. Inc. (2015). 